Research Article

\title{
Tension band wire fixation in olecranon fractures: a retrospective study
}

\author{
Mohammed KM. Ali*, Catherine Hatzantonis, C. A. Mbah, Amol Tambe, D. I. Clark
}

Department of Orthopaedics, Royal Derby Hospital Uttoxeter Rd, Derby DE22 3NE, United Kingdom

Received: 30 April 2016

Accepted: 10 June 2016

\section{*Correspondence:}

Dr. Mohammed KM. Ali,

E-mail: mohammedkhider84@hotmail.com

Copyright: () the author(s), publisher and licensee Medip Academy. This is an open-access article distributed under the terms of the Creative Commons Attribution Non-Commercial License, which permits unrestricted non-commercial use, distribution, and reproduction in any medium, provided the original work is properly cited.

\section{ABSTRACT}

Background: To evaluate the outcome of tension band wire fixation (TBW) of olecranon fractures in terms of bone union, surgical complications and return to theatre.

Methods: We retrospectively studied clinical patient notes and radiographs of fifty-two patients who underwent TBW fixation for olecranon fractures between January 2011 and January 2015, at an average follow-up of 36 months.

Results: This study included fifty-two patients (thirty-six females and sixteen males), with a mean age of 54 . All patients were treated by TBW fixation. Thirty patients had no complications post-operatively with good outcome. Sixteen patients $(31 \%)$ had metal work removal, and three patients $(6 \%)$ had non-union. Eighty-two percent of the removed metal work had two knots, $70 \%$ were intramedullary and $61 \%$ were proud.

Conclusions: Tension band wire fixation is a procedure with low risk of non-union; however, the percentage of metal work removal is significant. Using one knot, passing the K-wires across the anterior cortex, and flushing the proximal end will reduce the rate of return to theatre.

Keywords: Olecranon, Fractures, Tension band wire, Outcome

\section{INTRODUCTION}

Olecranon fractures are common injuries and constitute $10 \%$ of upper extremity fractures. ${ }^{1,2}$ These fractures commonly occur due to a direct impact to the point of the elbow or a fall onto an outstretched hand. Its subcutaneous location makes it vulnerable to direct trauma.

Olecranon fractures may also occur from a forceful triceps contraction against a fixed ulna. These fractures range from simple non-displaced fractures to complex fractures with dislocations of the elbow joint. Plain radiographs are commonly used to diagnose and plan management. CT scan may be required, in some cases, to assess the severity of the injury and plan fixation. ${ }^{3}$

Management of olecranon fractures with tension band wire fixation is indicated in simple displaced fractures and was first introduced by Weber and Vasey in $1963 .{ }^{4}$ This procedure, however, has a high prevalence of metalwork removal due to metalwork irritation. Metalwork irritation may be caused by Kirschner-wires loss of fixation and backing out of the insertion site. ${ }^{5}$ Our study evaluates TBW fixation of the olecranon in terms of bone union, surgical complication and percentage of secondary operations of metalwork removal.

\section{METHODS}

We retrospectively studied 52 patients with olecranon fractures who had TBW fixation between January 2011 and January 2015. All patients had isolated and closed olecranon fractures with no concomitant osseous injuries of the elbow. Open fractures were not included in this study.

The mean waiting time was 2.5 days, ranging from 1 to 8 days. Operations were performed either under general anaesthesia with local anaesthetic infiltration or regional block. Operations were performed in a lateral decubitus 
position using a pneumatic tourniquet. The mean tourniquet time was 45 minutes.

Through a posterior midline incision, the fracture was exposed with the proximal end curving to the lateral aspect of the olecranon. The operative technique involved two parallel $\mathrm{K}$-wires that were inserted from the tip of the olecranon into the ulna, and a figure-of-eight cerclage wire. The proximal ends of the K-wires were bent, and the cerclage wire was inserted through a predrilled transverse hole in the distal fragment and under the triceps tendon. The K-wires were then tightened to create inter-fragmentary compression in the figure of eight formation as shown in Figure 1.

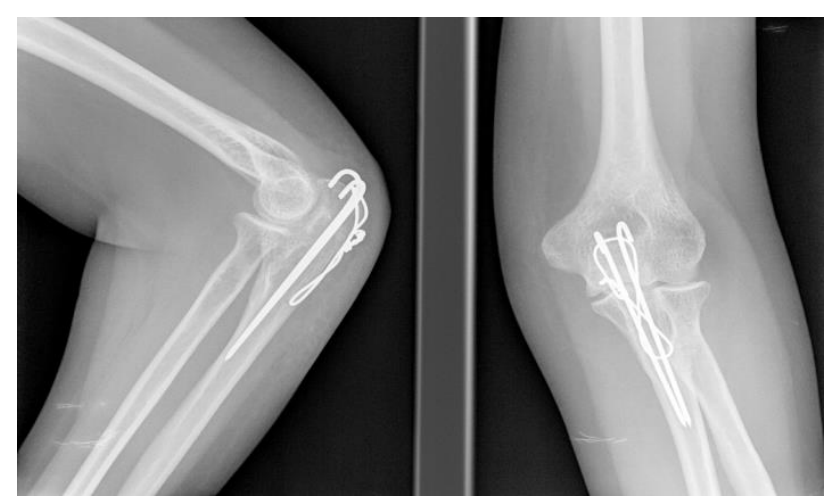

Figure 1: TBW of olecranon fracture.

For antimicrobial prophylaxis, Cefuroxime was used intravenously, with $1.5 \mathrm{~g}$ injected intra-operatively and $0.75 \mathrm{~g}$ injected after 8 and 16 hours. The operated arms of all patients were put in broad arm sling post-operatively. They were allowed immediate post-operative wrist and hand exercises. Patients were followed-up two weeks after surgery in outpatient clinics, where they had a wound checks and further instructions to start gentle elbow exercise. All patients had post-operative physiotherapy as per our local physiotherapy protocol.

The mean follow-up time was 36 months (ranging between 6-48 months). Minimal follow-up was 6 months or until further operative intervention was required. During the follow-up period, radiological union and implant failure or reduction loss were evaluated with elbow radiographs on anterior-posterior and lateral views.

\section{RESULTS}

This study included 36 females and 16 males, with a mean age of 54 years [range, 18-97 years]. According to Mayo classification system: 3 patients demonstrated Mayo type IA, 39 patients had Mayo type IIA and 10 patients demonstrated Mayo type IIB as given in Figure 2 and 3 .

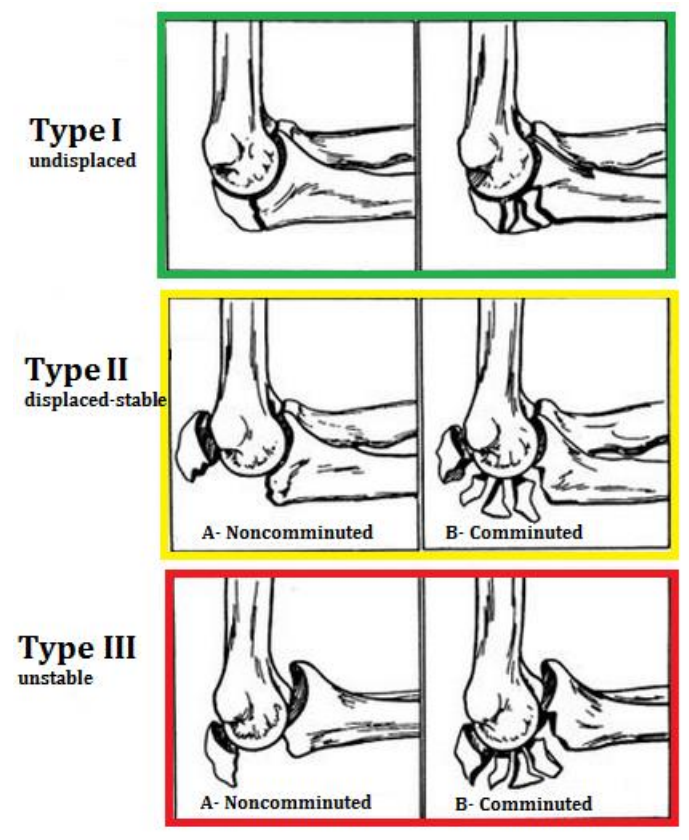

Figure 2: Mayo classification system of olecranon fractures.
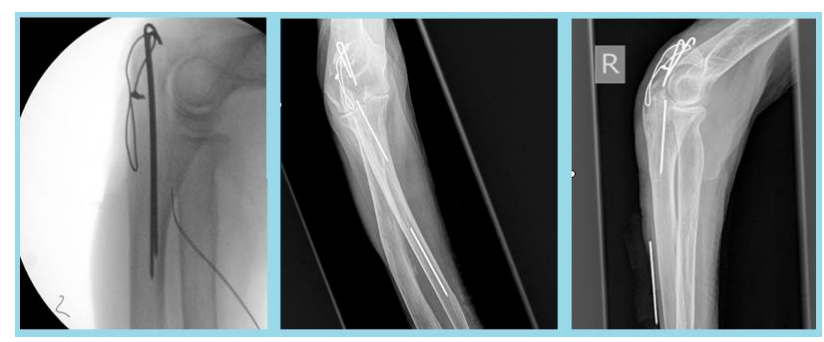

Figure 3: Plain radiographs of olecranon TBW demonstrating failed metalwork.

None developed wound infection or wound breakdown post-operatively. There were no recorded instances of ulnar nerve damage, myositis ossificans, or deep infections. There were also no cases of skin perforations by $\mathrm{K}$-wires.

Complete union was achieved in 49 (94\%) cases and three patients $(6 \%)$ developed non-union during the follow-up period. In the 49 cases; Anatomical reduction from time of surgery was maintained in all patients during follow-up. All patients were reported to have full supination, pronation and mean flexion arc of 10 to 130 degrees (+/_ 10).

Sixteen patients $(31 \%)$ required metal work removal. Thirteen cases of the removed metalwork were type IIA and 3 were type IIB. In 14 cases (12 type IIA and two type IIB), the reason for removal of metal work was direct complaint from the patient, and in two cases metal work failure was reported as shown in Figure 4. 


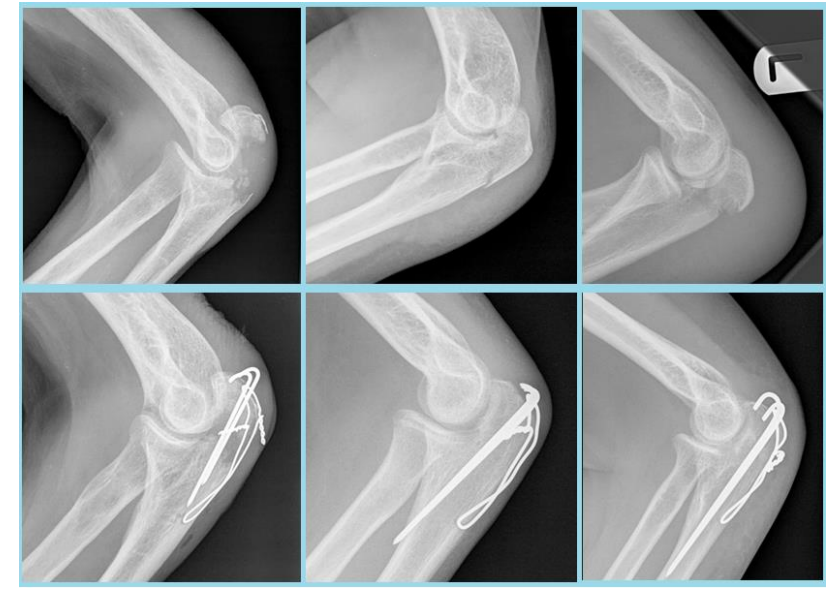

Figure 4: Radiographs demonstrating variation of olecranon fractures of Mayo classification of IIA, IA, and IIB (above, left to right) with TBW performed for each fracture pattern (below, left to right).

The technique of TBW fixation was also reviewed. In the use of the figure of eight formation, 17 patients had TBW with one knot while 35 were tightened using the two knots technique as in Figure 3. K-wire formation technique also differed with 29 patients had K-wires inserted intramedullary versus 23 patients with K-wires inserted to reach the anterior cortex as in Figure 3. Furthermore, 30 patients had K-wires left proud and 22 $\mathrm{K}$-wire fixations were put flush as in Figure 3. Metalwork removal was also analysed, and it was found that $82 \%$ of the removed metal work was fixed using two knots. $70 \%$ their K-wires were placed intramedullary and $61 \%$ had the K-wires left proud as presented in Figure 5.

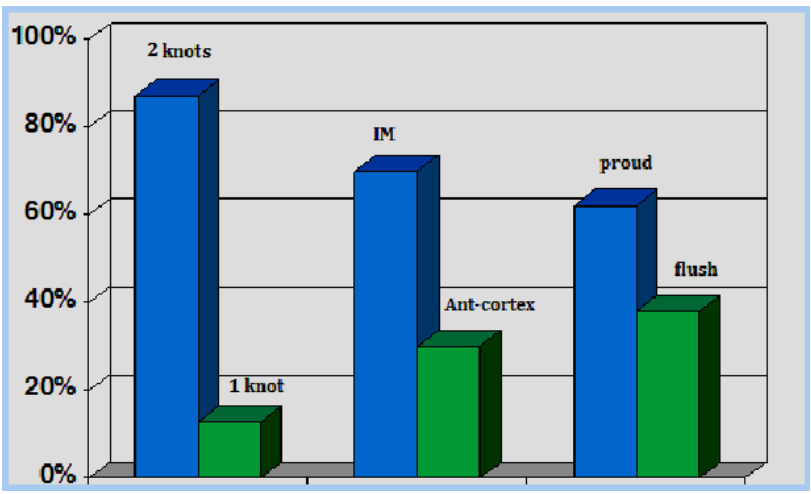

Figure 5: Surgical TBW techniques used in patients with removed metal work (blue) versus surgical TBW techniques in patients with metalwork remaining (green).

\section{DISCUSSION}

The final results in our study are considered to be satisfactory when compared with that of previously published literature with metalwork removal percentage ranging between 9-91\% and an average number of 36 patients as given in Table 1.
Table 1: Literature review of number of patients and percentage of metal work removal.

\begin{tabular}{|c|c|c|c|}
\hline Authors & $\begin{array}{l}\text { No. of } \\
\text { patients }\end{array}$ & $\begin{array}{l}\text { Metal } \\
\text { work } \\
\text { removal }\end{array}$ & $\begin{array}{l}\text { Mean } \\
\text { follow-up }\end{array}$ \\
\hline DelSole EM et al. ${ }^{6}$ & 23 & $9 \%$ & 84 months \\
\hline Chan KW. ${ }^{7}$ & 63 & $20 \%$ & $\begin{array}{l}\text { Not } \\
\text { available }\end{array}$ \\
\hline $\begin{array}{l}\text { Schliemann B et } \\
\text { al. }^{8}\end{array}$ & 13 & $91 \%$ & 43 months \\
\hline $\begin{array}{l}\text { Luigi Tarallo et } \\
\text { al. }{ }^{9}\end{array}$ & 33 & $33 \%$ & 33 months \\
\hline Uhlmann M. $^{10}$ & 26 & $73 \%$ & $\begin{array}{l}38.2 \\
\text { months }\end{array}$ \\
\hline Q-H Liu et al. ${ }^{11}$ & 32 & $15 \%$ & 21 months \\
\hline $\begin{array}{l}\text { Chalidis BE et } \\
\text { al. }{ }^{12}\end{array}$ & 62 & $82.3 \%$ & 96 months \\
\hline Akman et al. ${ }^{13}$ & 41 & $15 \%$ & 47 months \\
\hline Jensen. $^{14}$ & 29 & $79.2 \%$ & $\begin{array}{l}\text { Not } \\
\text { available }\end{array}$ \\
\hline
\end{tabular}

Based on our review of the literature, we can confirm a high rate of metal work removal. This would discourage surgeons from using this technique and subsequently, modifications of the TBW technique has been suggested by several authors with emphasis towards minimizing backing-out of K-wires. ${ }^{14-17}$

A study by Jensen and Olsen (1986) found a $79.2 \%$ overall removal rate of metalwork. They found that the primary concern was the backing-out of $\mathrm{K}$-wires and recommended modifications of the technique. ${ }^{18}$ These suggested modifications included looping of the proximal end of the K-wires instead of bending them, or, alternatively, using Netz-pins. ${ }^{17}$

Netz-pins are 2.0-mm-diameter stainless steel pins with a 1.1-mm-diameter hole drilled perpendicular to the long axis in the proximal end to pass the cerclage wire through it and hold the pins in place, thereby preventing backingout. Netz and Strömberg (1982) used Netz-pins in their patients instead of $\mathrm{K}$-wires, and achieved no reported cases of backing-out, with only $20 \%$ of metalwork removal. ${ }^{17}$ Conversely, Larsen and Lyndrup (1987) used Netz pins and reduced their overall removal rate from $68 \%$ to $52.4 \% .^{19}$ In another study by Larsen and Jensen (1991), 20 patients operated on with TBW and a modification of the Netz pin (consisting of flattening around the hole of the proximal end of the pin) achieved no cases of backing-out, but had a final metalwork removal rate of $70 \% .^{20}$

The AO recommends using a drill guide to introduce the first $1.6 \mathrm{~mm} \mathrm{~K}$-wire medially through the head of the olecranon.$^{21}$ This involves aiming of the drill towards the anterior cortex, passing as close as possible to the joint. One is then advised to leave enough space on the lateral side for the second K-wire. Then, it is advised to drill 
both cortices. Just after drilling the anterior cortex, the $\mathrm{K}$ wire should be drilled back approximately $1 \mathrm{~cm}$. This is required as the proximal bended ends of the $\mathrm{K}$-wires will finally be hammered into the bone and the distal ends should not protrude into anterior soft tissues. The K-wire is then cut obliquely $2 \mathrm{~cm}$ from the bone using the wire cutters.

Although studies have concluded no difference in complications or metalwork removal rate in the placement of the K-wires in TBW for olecranon fractures, our study has found $70 \%$ of those who had TBW required metal work removal, their $\mathrm{K}$-wires were placed intramedullary. ${ }^{7}$ In addition, Mullett et al (2000) studied the effect of $\mathrm{K}$-wire position on backing out of $\mathrm{K}$ wires in a group of 80 patients with closed transverse olecranon fractures with a minimum follow-up time of 9 months. ${ }^{22}$ The rate of wires backing out (as seen on $\mathrm{X}$ ray) was three times greater in patients who had K-wires passed down the long axis of the ulna rather than the $\mathrm{AO}$ recommendation of across the anterior cortex.

Studies have also found that the use of the figure of eight formation with two knots produces a symmetric tension at the fracture site and provides more rigid fixation than the use of a single knot. ${ }^{23,24}$ However, in our study we found that $82 \%$ of the removed metal work was fixed using two knots. We have found that having two knots will increase the chances of having metal work irritation whereas our patients with one-knot figure of eight formation did very well with a low percentage of metalwork removal.

\section{CONCLUSION}

It is our opinion that TBW of olecranon fractures yields reliable results in terms of fixation and healing, and does not possess a high rate of complications. However, the high rate of removal of metalwork may justify the exploration of other methods of fixation. We recommend when performing TBW fixation for olecranon fractures; the figure of eight should be tightened with one knot, the $\mathrm{K}$-wires should aim for the anterior cortex, and the $\mathrm{K}$ wires should be flush to reduce the chances of metal work irritation and backing-out of K-wires.

Funding: No funding sources Conflict of interest: None declared

Ethical approval: The study was approved by the institutional ethics committee

\section{REFERENCES}

1. Newman SD, Mauffrey C, Krikler S. Olecranon fractures. Injury. 2009;40(6):575-81.

2. Veillette CJ, Steinmann SP. Olecranon fractures. Orthop Clin North Am. 2008;39(2):229-36.

3. Newman SD, Mauffrey C, Krikler S. Olecranon fractures. Injury. 2009;40:575-81.
4. Weber BG, Unfallmed Berufskr VHZ. Osteosynthesis in olecranon fractures. 1963;56:90-6.

5. Romero JM, Miran A, Jensen CH. Complications and re-operation rate after tension-band wiring of olecranon fractures. J Orthop Sci. 2000;5(4):318-20.

6. DelSole EM, Pean CA, Tejwani NC, Egol KA. Outcome after olecranon fracture repair: Does construct type matter? Eur J Orthop Surg Traumatol. 2016;26(2):153-9.

7. Chan KW, Donnelly KJ. Does K-wire position in tension band wiring of olecranon fractures affect its complications and removal of metal rate? J Orthop. 2014;12(2):111-7.

8. Schliemann B, Raschke MJ, Groene P, Weimann A, Wähnert D, Lenschow $S$, et al. Comparison of tension band wiring and precontoured locking compression plate fixation in Mayo type IIAolecranon fractures. Acta Orthop Belg. 2014;80(1):106-11.

9. Tarallo L, Mugnai R, Adani R, Capra F, Zambianchi F, Catani F. Simple and comminuted displaced olecranon fractures: a clinical comparison between tension band wiring and plate fixation techniques. Arch Orthop Trauma Surg. 2014;134(8):1107-14.

10. Uhlmann M, Barg A, Valderrabano V, Weber O, Wirtz DC, Pagenstert G. Treatment of isolated fractures of the olecranon: percutaneous doublescrew fixation versus conventionaltension band wiring. Unfallchirurg. 2014;117(7):614-23.

11. Liu QH, Fu ZG, Zhou JL, Lu T, Liu T, Shan L, et al. Randomized prospective study of olecranon fracture fixation: cable pin system versus tension band wiring. J Int Med Res. 2012;40(3):1055-66.

12. Chalidis BE, Sachinis NC, Samoladas EP, Dimitriou CG, Pournaras JD. Is tension band wiring technique the "gold standard" for the treatment of olecranon fractures? A long term functional outcome study. J Orthop Surg Res. 2008;3:9.

13. Akman S, Ertürer RE, Tezer M, Tekeşin M, Kuzgun U. Long-term results of olecranon fractures treated with tension-band wiring technique. Acta Orthop Traumatol Turc. 2002;36(5):401-7.

14. Jensen CM, Olsen BB. Drawbacks of tractionabsorbing wiring (TAW) in displaced fractures of the olecranon. Injury. 1986;17:174-5.

15. Chaplin DM. Tension band wiring: a method to prevent "backing out" of the Kirschner wire. Injury. 1975;7:57.

16. Coleman NP, Warren PJ. Tension-band fixation of olecranon fractures. A cadaver study of elbow extension. Acta Orthop Scand. 1990;61:58-9.

17. Deliyannis SN. Comminuted fractures of the olecranon treated by the Weber-Vasey technique. Injury. 1973;5:19-24.

18. Netz P, Strömberg L. Non-sliding pins in traction absorbing wiring of fractures: a modified technique. Acta Orthop Scand. 1982;53:355-60.

19. Larsen E, Lyndrup P. Netz or Kirschner pins in the treatment of olecranon fractures? J Trauma. 1987;27:664-6. 
20. Larsen E, Jensen CM. Tension-band wiring of olecranon fractures with nonsliding pins. Report of 20 cases. Acta Orthop Scand. 1991;62:360-2.

21. Proximal forearm 21-B3.1 ORIF. AO Surgery Reference. AO Foundation. Available from: https://www2.aofoundation.org/wps/portal/surgery?

22. Mullett JH, Shannon F, Noel J, Lawlor G, Lee TC, O'Rourke SK. K-wire position in tension band wiring of the olecranon - a comparison of two techniques. Injury. 2000;31(6):427-31.
23. Hak DJ, Golladay GJ. Olecranon Fractures: Treatment Options. J Am Acad Orthop Surg. 2000;8:266-75.

24. Fyfe IS, Mossad MM, Holdsworth BJ. Methods of fixation of olecranon fractures. An experimental mechanical study. J Bone Joint Surg Br. 1985;67(3):367-72.

Cite this article as: Ali KMK, Hatzantonis C, Mbah CA, Tambe A, Clark DI. Tension band wire fixation in olecranon fractures: a retrospective study. Int Surg J 2016;3:1244-8. 